\title{
The challenges and conservation implications of bear bile farming in Viet Nam
}

\author{
Brian Crudge, Trang Nguyen and Cao Tien Trung
}

\begin{abstract}
Legalized trade in commercially farmed wildlife products is sometimes promoted as a conservation strategy. In theory, flooding the market with cheaper or better quality products will decrease the profitability of poaching. Bear bile is highly sought-after for use in traditional medicine and overhunting to supply the demand for bear parts has led to declining populations across Southeast Asia. Bear bile farming was established to help supply the high demand for bear bile. In Viet Nam it is legal to keep registered bears, but illegal to extract or sell bear bile. We conducted semi-structured interviews with 66 bear bile farmers in Viet Nam to examine the conservation implications of bear bile farming. The results show that demand for wild bear bile was not satisfied by the widespread availability of farmed bear bile. Farmers report a strong consumer preference and willingness to pay more for wild-sourced products. The existence of bear bile farms presents considerable challenges to law enforcement. The results suggest that bear bile farming in Viet Nam relies on restocking from wild populations, and farmers openly admit to extracting and selling bear bile, in clear violation of national legislation. The case of bear bile farming in Viet Nam provides an example of wildlife farming failing to reduce pressure on a once widely distributed and relatively abundant species. Research into consumer values, attitudes and behaviours will help to improve understanding of market drivers and help inform the design of effective species conservation and management strategies.
\end{abstract}

Keywords Bear bile, bile extraction, consumer preference, Traditional Asian Medicine, ursodeoxycholic acid, Ursus thibetanus, wildlife farming, Viet Nam

Supplementary material for this article is available at https://doi.org/10.1017/So030605317001752

Brian Crudge (Corresponding author) Free the Bears, PO Box 723, House 26, Street 334, BBK1, Phnom Penh, Cambodia. E-mail briancrudge@gmail.com

Trang NGUYen* Durrell Institute of Conservation and Ecology, University of Kent, Kent, UK

Cao Tien Trung Centre for Environment and Rural Development, Vinh University, Vinh City, Viet Nam

${ }^{*}$ Also at: WildAct Vietnam, Hanoi, Viet Nam

Received 31 August 2017. Revision requested 3 October 2017.

Accepted 15 November 2017. First published online 2 July 2018.

\section{Introduction}

Outh-east Asia is in the midst of a wildlife crisis (Wilcove $\checkmark$ et al., 2013). Overhunting is the greatest and most immediate threat to the survival of the majority of the region's threatened vertebrates, caused in part by the growing demand for wild meat and wildlife-derived medicinal products (Harrison et al., 2016). Commercial farming of wildlife and a legalized trade in farmed wildlife products are sometimes promoted as conservation strategies and potential solutions to the wildlife crisis (Bulte \& Damania, 2005).

Bears, their parts and derivatives are highly sought-after for use in Traditional Asian Medicines. Hunting and trade are significant threats to Asiatic black bear Ursus thibetanus and sun bear Helarctos malayanus, and have led to population declines and extirpations throughout much of their historic ranges. Both species are classified as Vulnerable on the IUCN Red List, and international commercial trade is prohibited under CITES Appendix I (Garshelis \& Steinmetz, 2016; Scotson et al., 2017). Bear bile farming was established in Viet Nam in the 199os in response to increasing consumer demand for bear bile ( $\mathrm{Vu}, 2 \mathrm{O10})$, which contains the therapeutic component ursodeoxycholic acid. Although the term 'bear bile farm' suggests that bears are bred at these facilities, in reality little breeding occurs and most bears are wildcaught (Foley et al., 2011; Livingstone \& Shepherd, 2016).

Viet Nam became a signatory to CITES in 1994, thereby prohibiting cross-border trade in bears. In 2005 domestic regulations were introduced to limit the number of wildsourced bears entering bear bile farms. Bear owners were required to register and microchip every bear by 28 February 2005. However, it remained illegal to extract bile from the bears (Nguyen, 2007; Willcox et al., 2016). Government Decree 32/2006/ND-CP on the Management of Endangered, Precious, and Rare Species of Wild Plants and Animals, dated 30 March 2006, lists sun bears and Asiatic black bears as Group $1 \mathrm{~B}$ protected species, prohibiting their exploitation and use for commercial purposes, including hunting, trading, advertising, transport, and slaughter. Therefore, although individuals are permitted to keep bears that were registered on or before 28 February 2005, it is illegal to extract or sell bile from those bears, and to keep unregistered bears or source new bears from the wild.

Despite the introduction of regulations, law enforcement deficiencies have allowed the trade in live wild-caught bears and the extraction of bear bile to continue (Burgess et al., 2014; Willcox et al., 2016). Recent nationwide surveys in Viet Nam have shown that wild bear populations declined 
throughout the country at a time when the bear bile industry was growing rapidly, suggesting that the establishment of bear bile farms had a negative impact on wild bear populations (Crudge et al., 2016). Although demand for wild bears and their body parts continues to persist (Foley et al., 2011; Burgess et al., 2014; Crudge et al., 2016; Livingstone \& Shepherd, 2016; Willcox et al., 2016; Nijman et al., 2017), reports indicate that the number of bears kept on farms in Viet Nam is in decline, from a peak of almost 4,500 in 2005 to c. 3,500 in 2010 and further decreasing to 1,250 in 2015 (Willcox et al., 2016).

This study aims to investigate the reasons for the decline in the number of bears held in bile farms in Viet Nam. We consider the conservation potential of bear bile farming in Viet Nam and determine if any conclusions can be applied to the bear bile industry beyond Viet Nam and to commercial farming of wildlife in general.

\section{Study area}

Hanoi, Nghe An Province, Ho Chi Minh City and Binh Duong Province were selected as survey sites based on their relatively large populations of captive bears (based on 2006 data from the Ministry of Agriculture and Rural Development; Supplementary Table 1) and their geographical representation of northern, north-central and southern Viet Nam. In Viet Nam, demand from urban centres has been identified as a primary driver for the hunting of wild animals (Donovan, 2004; Brooks et al., 2010; Drury, 2011). Hanoi and Ho Chi Minh City are Viet Nam's two largest cities. Binh Duong Province is immediately north of $\mathrm{Ho}$ Chi Minh City and its southern districts of Di An and Thuan An are highly urbanized and are now encompassed within the Ho Chi Minh City metropolitan area. Vinh City, the provincial capital of Nghe An, is the largest city on the north-central coast of Viet Nam.

\section{Methods}

\section{Semi-structured interviews}

We conducted semi-structured interviews with bear bile farmers and former bear bile farmers in Hanoi, Nghe An Province, Ho Chi Minh City, and Binh Duong Province between March and July 2016. Semi-structured interviews are most suitable in situations where there will only be one opportunity to interview a participant (Newing, 2011; Bernard, 2011). Unlike structured interviews such as questionnaires, which are used for large-scale quantitative analyses, semistructured interviews focus on gathering data from a relatively small set of informants, to gain insight into underlying processes, values and relationships that can lead to specific outcomes (Drury, 2009). Interviews were conducted using an interview guide (Supplementary Material 1) designed to elicit data on key topics but also allowing interviewers to be guided by the pace and flow of the conversation and follow the interviewees' leads on key topics.

All interviews were conducted in Vietnamese by native Vietnamese speakers. In Hanoi, Ho Chi Minh City and Binh Duong surveys were conducted by one experienced Vietnamese researcher, data in Nghe An were collected by eight volunteers with formal training in research methodology from Vinh University. Potential interviewees were identified based on prior knowledge of farm locations, local knowledge of researchers, and by questioning local members of the public such as residents, shop owners and motorbike taxi drivers.

Researchers identified themselves as associates of Vinh University, and explained they were interested in studying the economics of commercial wild animal farming and its potential as a source of income in rural or semi-rural areas. Because of the sensitive nature of the topic, respondents were informed that interviews would be anonymous and that no personal identifying information would be recorded. Verbal consent was obtained from each respondent before the interview and respondents could refuse to answer any question or end the interview at any point. All data collected were anonymous.

\section{Data analysis}

As a result of the semi-structured design of the survey and the sensitivity of the topic, the number of responses varied between questions. Here we present response frequencies as percentages and fractions of the total number of responses to each question. For analysis, responses that were stated as a range (e.g. 2000-2008) were standardized to the midpoint of the stated range (e.g. 2004).

Data collected during the interviews are supplemented with data obtained from the Ministry of Agriculture and Rural Development (Supplementary Table 1). Data from Ho Chi Minh City and Binh Duong are pooled for analysis because of their close geographical proximity. It should be noted that during the interviews it became apparent that occasionally bears were owned collectively by a small group of people. However, only one person was interviewed at any one location and the possibility that more than one interviewee provided information on the same bear or bear farm is negligible.

Data were provided by respondents on both the highest and lowest trading values of bear bile. Differences between the related points were normally distributed and a paired $T$-test was used to compare the differences between the current price for bear bile and the highest trading value across the country. A non-parametric Mann-Whitney U test was used to examine the difference between the frequencies of bile extraction between bears of reportedly wild origin and those of captive origin, as well as for the highest sale price of wild and 
captive bear bile. Prices were converted to USD (at the currency exchange rate from the month of response). Bears are a protected species in Viet Nam and extraction and sale of bile are illegal, therefore trade values are not presented here, to avoid unnecessarily inciting unlawful behaviours.

\section{Results}

We conducted semi-structured interviews with a total of 66 current or former bear bile farmers in Hanoi $(n=32)$, Nghe An Province $(n=23)$, Ho Chi Minh City and Binh Duong Province $(\mathrm{n}=11)$. Nine farmers declined to participate in the survey. The largest group of respondents $(48 \%, 32 / 66)$ were current owners of bear bile farms, followed by former owners $(33 \%, 22 / 66)$, current workers $(8 \%, 5 / 66)$, immediate family members of current and former owners $(8 \%, 5 / 66)$, and former workers $(3 \%, 2 / 66)$.

\section{Growth of an industry}

The majority of surveyed farms $(73 \%, 46 / 63)$ were established during 1996-2005. The surveyed farms fall into three categories: small household businesses with 1-9 bears $(36 \%, 8 / 22)$, medium commercial businesses with $18-40$ bears $(50 \%, 11 / 22)$ and larger commercial enterprises with $70-100$ bears $(14 \%, 3 / 22)$.

In 2006, the only year for which there is complete data available, the number of recorded bears in farms in Viet Nam was 4,349 (Ministry of Agriculture and Rural Development data, Supplementary Table 1). Ten out of 59 provinces contained $73 \%(3,184 / 4,349)$ of the captive bear population (Fig. 1), with bear farms being concentrated near large urban populations (Fig. 2). The majority (96\%, $4,160 / 4,349$ ) of registered bears were Asiatic black bears; the remaining $4 \%(189 / 4,349)$ were sun bears.

Two thirds of respondents $(67 \%, 29 / 43)$ reported that their founder stock was supplemented with additional individuals, whereas the others $(33 \%, 14 / 43)$ cited lack of available space as the primary reason for not expanding. Of the farmers that reported supplementing the founder stock, $36 \%$ $(8 / 22)$ added $2-9$ bears, $50 \%(11 / 22)$ added $18-40$ bears and $14 \%(3 / 22)$ added $70-100$ bears. The mean percentage increase between founder and maximum number of bears held on the farms was $964 \%$ ( $S D \pm 857$ ).

\section{Supply and demand}

All respondents $(n=42)$ stated that at the height of the industry the supply of farmed bear bile could not meet the demand. Interviewees reported 'people queuing up to buy bile' and that 'even with the whole village keeping bears they could not meet the demand'. Of those that responded, all $(n=39)$ reported that the farms needed more bears to meet

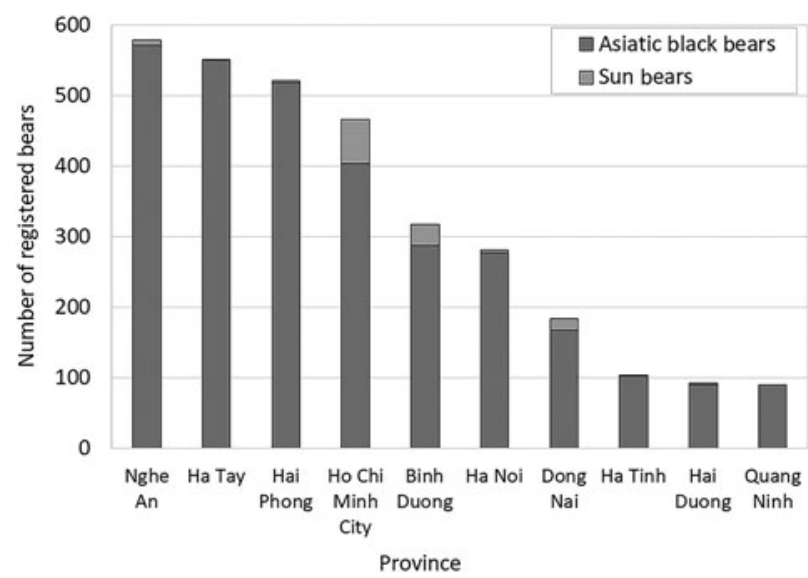

FIG. 1 The number of registered bears in 2006 in the 10 out of 59 provinces in Viet Nam with 90 or more registered bears,

accounting for $73 \%(3,184 / 4,349)$ of the captive bear population at that time (data sourced from the Ministry of Agriculture and Rural Development, Supplementary Table 1).

the demand. All respondents $(n=66)$ reported that the consumer demand for farmed bear bile is now decreasing. Eight interviewees (12\%) reported that there was an initial increase in demand since bear bile farms were first established, and three stated that this was followed by a decline beginning in 2008-2010. Poor quality bile was the primary reason given for decreasing consumer demand, reported by $76 \%$ (50/66) of respondents. Of those, $18 \%(9 / 50)$ reported that poor quality bile is a result of high bile extraction rates and $64 \%(42 / 66)$ reported that consumers are also concerned about the authenticity of the bile that is being sold.

All respondents $(n=66)$ reported that bile from wild bears is of better quality than bile from bear bile farms. Six interviewees specifically mentioned that wild bear bile is better because of the quality of food in the wild, and the fact that the bears do not undergo regular extractions. Almost all farmers $(98 \%, 65 / 66)$ felt that the quality of the bile is affected by a bear's ability to move and forage.

All interviewees $(n=66)$ reported that consumers care about the difference between wild-sourced and farmed bear bile, with the preference being for bile from wild bears. The majority of respondents $(92 \%, 61 / 66)$ reported that bile from wild bears is more expensive. Over half of the respondents $(53 \%, 35 / 66)$ specifically stated that bile from a bear living in the forest is the most valuable, followed by bile from a bear that was caught in the wild but kept on a bile farm, with the least valuable being bile from a captive-born bear. The mean stated price for wild bear bile $(n=3)$ was 12 times higher than the current mean price for farmed bear bile.

\section{Economics of bile farming}

Interviewees reported a decrease in the amount consumers are willing to pay for farmed bear bile. The price of bear bile 




FIG. 2 Map of Viet Nam showing survey sites in Hanoi, Nghe An, Ho Chi Minh City and Binh Duong and the number of bears registered in each province in 2006 (data on the number of registered bears sourced from the Ministry of Agriculture and Rural Development, Supplementary Table 1). has reduced by a mean of $82 \pm$ SD $13.22 \%(n=62)$ in recent years. There is a significant difference between prices of farmed bear bile at the height of the industry and the current low values $(t=17.467, \mathrm{df}=65, \mathrm{P}<0.05)$.

Bile is extracted more frequently from reportedly wildcaught bears than captive-born bears $(U=128.5, W=948.5$, $\mathrm{P}<0.05)$. However, although wild-caught bears are undergoing more frequent extractions, and the quality of the bile reportedly decreases with increasing extraction rates, the highest value of wild-caught bear bile is significantly higher than that of captive-born bear bile $(U=151.0$, $W=971.0, \mathrm{P}=0.01$ ).
Food for the bears was identified as the greatest expense incurred after the initial costs of purchasing a bear and building a cage. There is a significant difference between current expenditure on food and expenditure at the time when the price for bear bile was high $(t=9.746, \mathrm{P}<0.05)$. Following the decline in income, expenditure on food has dropped by $87 \%$, from a mean of USD 35 per bear per month $(n=62)$ (at the 2010 exchange rate) to a mean of USD 4 per bear per month $(n=8)$ (at the 2016 exchange rate). Bile is extracted on average $4.39 \pm$ SD 4.2 times per bear per year $(n=38)$. The mean volume of bile obtained per extraction is $132 \pm \mathrm{SD} 38.5 \mathrm{ml}(\mathrm{n}=35)$, meaning one bear can yield c. $578 \mathrm{ml}$ of bile per year. 
The mean lifespan of bears in bile farms, reported by $74 \%$ (17/23) of interviewees in Nghe An (this question was only asked in this region), is $7.56 \pm$ SD 1.34 years. The majority of respondents $(62 \%, 34 / 55)$ reported old age and disease as the main causes of death for bears on the farms, nine interviewees (16\%) attributed death specifically to digestive problems, and three respondents (5\%) reported that the bile extraction process was the main cause of death. Three farmers reported killing the bears after they reached 8 years of age. Most farmers $(79 \%, 41 / 52)$ reported that farmed bear bile is now too cheap and that keeping bears no longer provides any benefit to them.

Despite these changes in the economic viability of bear bile farming, some farmers continue to keep bears to sell bile occasionally or keep it for personal use.

\section{Founding stock and captive breeding}

Although there was a large amount of uncertainty, most respondents $(62 \%, 40 / 65)$ reported that the bears on their farms were wild-caught, a minority $(14 \%, 9 / 65)$ claimed that the bears were sourced from other farms, and $26 \%$ (17/65) stated that they did not know the origin of the bears. According to respondents, the average size of the founder stock for the bear bile farms was $3 \pm$ SD 1.5 bears $(n=35)$. The majority of respondents $(65 \%, 43 / 66)$ reported that bears were purchased as adults ( $>_{2}$ years), whereas the minority $(32 \%, 21 / 66)$ reported buying juvenile bears $(<2$ years), and two $(3 \%, 2 / 66)$ interviewees did not know the age of the bears when purchased.

Only $12 \%(8 / 66)$ of respondents reported that the farms had attempted to breed bears and only four farms $(6 \%, 4 / 66)$ reported successful breeding. Of those four, three reported that bears were born but died after 1 week. One interviewee reported that the farm started with three bears in 1998 and increased to 70 by breeding bears on the farm, although this report was not substantiated by other means. Most respondents $(94 \%, 62 / 66)$ reported that breeding bears is difficult, and the majority $(91 \%, 60 / 66)$ stated that they did not know of anybody who had done so successfully.

\section{Law enforcement and violations}

Almost all respondents $(95 \%, 63 / 66)$ admitted to regularly extracting bile from bears, a practice which is a clear violation of national legislation. The majority of interviewees $(95 \%, 63 / 66)$ reported personal use of bile extracted from bears on their own farm. Only five interviewees admitted to advertising the sale of bear bile, all of whom placed signs in front of the farm or house.

One third of interviewees $(33 \%, 22 / 66)$ reported that their customers requested to purchase bear gallbladder instead of bile, and $46 \%(30 / 65)$ admitted that customers requested bear paws or other parts to consume as food. Farmers generally did not provide the requested items unless the bear died of other causes. However, nine farmers (14\%) admitted to killing bears and selling their parts before the government registration scheme in 2005. Of the surveyed farms, 10 (16\%) were established from 2006 onward and a third of farmers $(32 \%, 18 / 57)$ admitted to purchasing bears after 2005.

Of the 39 respondents that commented on the implications of registering with the Forest Protection Department, $13(33 \%)$ mentioned the authorities visiting the farms. Eight farmers $(21 \%)$ reported that registration made things complicated or troublesome, specifically that they were unable to trade freely $(10 \%, 4 / 39)$. A small number of farmers $(13 \%, 5 / 39)$ mentioned having to pay unofficial fees to the authorities, and 39\% (16/41) reported having paid the Forest Protection Department a small fee for registering the bears.

The majority of respondents $(75 \%, 44 / 59)$ reported that the Forest Protection Department conducted inspections of the farms, whereas others $(25 \%, 15 / 59)$ stated that no inspections were carried out. Farms that were inspected were typically visited by authorities once or twice per year (mean $1.8 \pm \mathrm{SD} 0.5, \mathrm{n}=31$ ). Only $5 \%$ of interviewees $(3 / 64)$ reported that the authorities have issued fines, specifically for selling bear bile. Half of the respondents $(51 \%, 31 / 61)$ admitted to killing bears when closing the farms, and more than half $(54 \%, 33 / 61)$ admitted to selling either live bears or bear parts. Eleven interviewees (18\%) reported that bears had been handed over to the Forest Protection Department or a rescue centre.

\section{Decline of an industry}

Although some farms $(13 \%, 4 / 31)$ closed before 2006 , the majority of respondents $(87 \%, 27 / 31)$ reported that their farms closed between 2007 and 2014. A third of respondents (33\%, 17/52; including farmers who were still keeping bears but were considering stopping) mentioned government interventions, specifically inspections and discouragement, as reasons for discontinuing bear bile farming. The majority $(79 \%, 41 / 52)$ reported that one of the main reasons for stopping farming was because bear bile is now too cheap to sell; $11 \%(7 / 66)$ of respondents mentioned that using bear bile was no longer fashionable, and $9 \%(6 / 66)$ mentioned that consumers think that farmed bear bile is ineffective, specifically that the effectiveness of farmed bear bile was overstated and does not meet their expectations. Only two respondents mentioned the availability of better alternative medicines. Intervention by government authorities, including discouraging bear bile farming, making it difficult to sell, and shaming people was reported by $18 \%$ of respondents $(12 / 66)$ as contributing to the decreasing demand for farmed bear bile. All respondents $(n=62)$ believed that local wild bears are rare or extinct. However, most respondents 
(93\%, 42/45) also believed that bear bile farming helped to protect wild bear populations.

\section{Discussion}

Contrary to the belief of bear bile farmers, there is no evidence to suggest that bear bile farming has had a positive impact on wild bear populations in Viet Nam. At the 2012 IUCN World Conservation Congress, IUCN members passed a motion to phase out bear bile farming (IUCN, 2012). The government of Viet Nam now acknowledges that bear bile farming has had a negative impact on wild populations and in July 2017 signed an agreement to end bear bile farming (T. Bendixsen, 2017, pers. comm.).

The majority of surveyed farms were established during 1996-2005. Most registered bears in 2006 were concentrated around the urban centres of Hanoi, Ho Chi Minh City, and Vinh City in Nghe An Province. This supports the supposition that rapid growth in urban prosperity during 19902010 led to an increasing demand for wildlife products in Viet Nam (Venkataraman, 2007; Drury, 2009).

Five criteria have been identified, all of which must be met in order for wildlife farming to benefit species conservation (Tensen, 2016): (1) the legal products form a substitute, and consumers show no preference for wild-caught animals; (2) a substantial part of the demand is met, and the demand does not increase because of the legalized market; (3) the legal products are more cost-efficient, to combat the black market prices; (4) wildlife farming does not rely on wild populations for restocking; and (5) illegal products are not laundered into the commercial trade. Based on the results presented here, bear bile farming in Viet Nam, under past and current conditions, fails to meet any of these criteria and therefore does not have the potential to benefit species conservation.

Noting that bears have been a fully protected species in Viet Nam since 2006 and that there is no legal market for bear bile in the country, the results of this study show that the demand for wild bear bile was not satisfied by the widespread availability of farmed bear bile. Despite a substantial growth in the number of bears being held on farms, respondents reported that at the height of the industry the supply of farmed bear bile could not meet the demand. The subsequent reduction in demand for farmed bear bile is partially attributed to consumer dissatisfaction with farmed bear bile as a substitute for bile sourced from wild bears. Rather than consumers being dissatisfied with bear bile in general, the farmers attribute the dissatisfaction to the poor quality of farmed bear bile, an issue not associated with bile sourced from wild bears.

Bear bile farmers report a strong consumer preference for wild-sourced bear bile. This distinction is reflected in the price that consumers are willing to pay, with $92 \%$ of respondents reporting that bile from wild bears is more expensive. This finding is supported by surveys in rural villages throughout Viet Nam in 2015, which found that the average reported value of bile from wild bears was c. 10 times higher than that of farmed bear bile (BC, unpubl. data).

The perceived better quality and variety of food in the wild and the fact that wild bears do not undergo regular extractions are factors contributing to the strong preference for bile from wild bears. Consumers are also concerned about the efficacy of farmed products and are wary of fakes, which probably contributes to their willingness to pay more for wild bear bile. There is greater trust in more expensive medicines and an assumption that price relates to quality (Dutton et al., 2011). Therefore, the fact that bile and gallbladders from wild bears are more expensive may allay consumer concerns about efficacy and authenticity.

Although bear bile farming appears to have been highly profitable in the past, even with additional income from selling the parts of a deceased bear, it is now unlikely to be cost-efficient enough to combat black market prices. Opportunistic or indiscriminate hunting methods such as snaring, commonly used throughout Viet Nam and South-east Asia to catch bears and other terrestrial mammals, do not require much skill on the part of the hunter and do not incur substantial financial or opportunity costs because snares can be made easily at home or purchased cheaply (Harrison et al., 2016). As a result of the low investment costs and the potentially high profits from the sale of a wild bear or other high-value species, bear bile farming is unlikely to be more cost-efficient than hunting under the current conditions of under-resourced law enforcement and high consumer demand for wild-sourced products.

Although in China many bear farms now appear to have active breeding programmes, restocking from the wild continues and there is no evidence of breeding of farmed bears anywhere in South-east Asia (Garshelis \& Steinmetz, 2016). It is clear from our data that bear bile farming in Viet Nam is heavily reliant on restocking from wild populations. Farmers reported that bears on farms lived c. 7.5 years. Some admitted to killing bears after they reached 8 years of age. Assuming that bile extraction begins at c. 3 years (Maas, 2000), this supports the findings of Nguyen (2007) that because of poor husbandry and excessive bile extraction, most captive bears do not survive $>4-5$ years of exploitation, after which the owners have to procure new bears caught from the wild. The data do not indicate that there has been sufficient captive breeding of bears on bile farms to sustain a viable population. The majority of farmers reported that breeding bears on farms is difficult and most $(61 \%)$ reported that the bears were wild-caught. This finding is supported by the incidence of snare injuries observable in the captive bear population and widespread documented declines in wild bear populations throughout 
the region coinciding with the establishment of bear bile farms (Loeffler et al., 2009; Crudge et al., 2016; Livingstone \& Shepherd, 2016).

The existence of bear bile farms presents considerable challenges to law enforcement. Even though almost all interviewees (95\%) admitted to regularly extracting bile, and half (51\%) admitted to killing bears when closing the farms, which are clear violations of national legislation, only $5 \%$ of respondents reported having ever been issued fines. This indicates a discrepancy between violation and prosecution rates. However, government interventions, specifically inspections and discouragement, were mentioned by a third of respondents as reasons for discontinuing bear bile farming.

The Forest Protection Department and provincial authorities in Viet Nam lack the resources and capacity to monitor bear farms using microchip scanners that were introduced when registration of bears became mandatory (Willcox et al., 2016). The resulting uncertainty about the origin of an animal impedes effective law enforcement. With no reliable, readily-available method to distinguish between bears or bear bile from wild or farmed sources, the potential for laundering is significant. In addition, a number of farmers admitted to paying small or unofficial fees to the authorities, suggesting there may be barriers to strict regulation of wildlife farms. Despite prohibition of domestic and international trade in bears and their parts, trade and trafficking is widespread (Burgess et al., 2014; Willcox et al., 2016). In an assessment of all reported bear-related seizures across Asia during 2000-2011, Viet Nam was identified as a significant source country for live bears, with the second highest trade volume (152 live bears), and it is inferred that seized live bears were intended to stock bear bile farms (Burgess et al., 2014).

Viet Nam's regulation on the Management of Captive Bears (Decision 95 QD/2008/BNN-KL) prohibits keeping bears in facilities that do not meet certain minimum requirements, including stipulations that bear farmers must ensure they have sufficient finances to take care of the bears and that bears must receive sufficient food and water daily. The health and welfare implications of bear bile farming are important considerations for its long-term viability, which need to be taken into account by other nations in the region (and by Viet Nam if regulations were to change in the future). A comprehensive assessment of these issues is beyond the scope of this study but they are discussed elsewhere (Maas, 2000; Loeffler et al., 2009). However, our study shows that there has been a significant decrease in farmers' monthly expenditure on bear food during 2010-2016, suggesting that, in contravention of regulations and the principles of animal welfare, bears on farms are currently not receiving sufficient sustenance.

Proponents of commercial wildlife farming often argue that other, more conventional conservation interventions are failing to protect the most threatened and most soughtafter species, and that alternative strategies should be tested (Bulte \& Damania, 2005). Because of the potentially high risks of increased threats (should the market not react as expected) and lack of empirical evidence, much of the debate around this contentious issue relies on model-based approaches and economic theory (Tensen, 2016). The case of bear bile farming in Viet Nam provides an example of wildlife farming failing to sufficiently reduce pressure on a once widely distributed and relatively abundant species. Commercial bear bile farming has been practiced since the 1970s (Foley et al., 2011). Despite the fact that $>10,000$ bears are held on farms in Asia, demand for wild bear bile and gallbladders remains high (Nijman et al., 2017) and it is unlikely that commercial trade in bear products will become sustainable.

The findings presented here highlight the difficulties in regulating large-scale commercial farming of wildlife. It is clear that bear bile farming in Viet Nam fails to meet any of the criteria necessary for commercial wildlife farming to benefit conservation, and many bear farms do not comply with government regulations as they continue to extract and sell bear bile. This raises important considerations for the continued existence of wildlife farms in Viet Nam and the government's response. If commercial wildlife farming is to be of benefit to species conservation, deficiencies need to be addressed and resources will need to be directed towards improving regulatory compliance on farms, reforming farming practices, increasing effective law enforcement efforts, and changing consumer preferences and behaviours.

The results of this study have important implications for commercial wildlife farming as a conservation strategy. Bear bile farming expanded rapidly in Viet Nam, to the detriment of wild bear populations. Yet the widespread availability of farmed bear bile has failed to satisfy consumer demand. Unlike farming of certain relatively fecund species that are bred commercially for their skins (e.g. crocodiles; Corey et al., 2017) or meat (e.g. snakes; Aust et al., 2017), we argue that, without a considerable shift in consumer preferences, commercial farming will not result in positive conservation impacts for species such as bears, rhinoceroses and tigers, which are exploited primarily for medicinal products, the potency of which is believed to be greatest when obtained from wild individuals. Research into consumer values, attitudes and behaviours will help improve our understanding of market drivers and help inform the design of effective species conservation and management strategies.

\section{Acknowledgements}

This project was funded by a Perth Zoo Wildlife Conservation Action grant awarded to Free the Bears. We thank Perth Zoo for their continued support of bear conservation in South-east Asia, the volunteers and assistants for sharing their local knowledge and for their support during data collection, and Matt Hunt, Nev Broadis, David Roberts 
and two reviewers for their critiques. Thanks to Lim Thona for assistance with the production of the map. Research was carried out in association with the Centre for Environment and Rural Development at Vinh University, which issued the necessary research permits and approval (Số: 1289 /QĐ-ĐHV). Dedicated to Dr Tony Whitten, for his genius and his works.

\section{Author contributions}

Research concept development: BC, TN, CTT; research design: BC, $\mathrm{TN}$; project implementation: $\mathrm{BC}, \mathrm{TN}, \mathrm{CTT}$; data collection: $\mathrm{TN}$, CTT; data analysis and interpretation: $\mathrm{BC}, \mathrm{TN}$; manuscript preparation: $\mathrm{BC}, \mathrm{TN}$

\section{Conflicts of interests}

None.

\section{Ethical standards}

Research was conducted in compliance with the principles and obligations to human subjects detailed in the Ethical Guidelines issued by the Social Research Association.

\section{References}

Aust, P.W., Van Tri, N., Natusch, D.J.D. \& Alexander, G. (2017) Asian snake farms: conservation curse or sustainable enterprise? Oryx, 51, 498-505.

Bernard, H.R. (2011) Research Methods in Anthropology: Qualitative and Quantitative Approaches. 5th edition. AltaMira Press, Lanham, USA.

Brooks, E.G.E., Roberton, S.I. \& Bell, D.J. (2010) The conservation impact of commercial wildlife farming of porcupines in Vietnam. Biological Conservation, 143, 2808-2814.

Bulte, E.H. \& Damania, R. (2005) An economic assessment of wildlife farming and conservation. Conservation Biology, 19, 1222-1233.

Burgess, E.A., Stoner, S.S. \& Foley, K.-E. (2014) Brought to bear: an analysis of seizures across Asia (2000-2011). TRAFFIC, Petaling Jaya, Selangor, Malaysia.

Corey, B., Webb, G.J.W., Manolis, S.C., Fordham, A., Austin, B.J., Fukuda, Y., Nicholls, D. \& SAalfeld, K. (2017) Commercial harvests of saltwater crocodile Crocodylus porosus eggs by Indigenous people in northern Australia: lessons for long-term viability and management. Oryx, https://doi.org/10.1017/ So030605317000217.

Crudge, B., Wilkinson, N.M., Do, V.T., Cao, T.D., Cao, T.T., Weegenaar, A. \& Hunt, M. (2016) The status and distribution of bears in Vietnam, 2016. Technical Report. Free the Bears/Animals Asia, Viet Nam.

Donovan, D. (2004) Cultural underpinnings of the wildlife trade in Southeast Asia. In Wildlife in Asia: Cultural Perspectives (ed. J. Knight), pp. 88-111. RoutledgeCurzon, New York, USA.

DruRy, R. (2009) Reducing urban demand for wild animals in Vietnam: examining the potential of wildlife farming as a conservation tool. Conservation Letters, 2, 263-270.

DruRY, R. (2011) Hungry for success: urban consumer demand for wild animal products in Vietnam. Conservation \& Society, 9, $247-257$.
Dutton, A.J., Hepburn, C., \& MacDonald, D.W. (2011) A stated preference investigation into the Chinese demand for farmed vs. wild bear bile. PLOS ONE, 6, e21243.

Foley, K.E., Stengel, C.J. \& Shepherd, C.R. (2011) Pills, powders, vials and flakes: the bear bile trade in Asia. TRAFFIC Southeast Asia, Petaling Jaya, Selangor, Malaysia.

Garshelis, D. \& Steinmetz, R. (2016) Ursus thibetanus. The IUCN Red List of Threatened Species. Https://doi.org/10.2305/IUCN.UK. 2016-3.RLTS.T22824A45034242.en [accessed 23 May 2018].

Harrison, R.D., Sreekar, R., Brodie, J.F., Brook, S., Luskin, M., O'KeLly, H. et al. (2016) Impacts of hunting on tropical forests in Southeast Asia. Conservation Biology, 30, 972-981.

IUCN (2012) Motions Issued on 8 July 2012 World Conservation Congress, Jeju, Republic of Korea, 6-15 September 2012. Congress Document WCC-2012-9.6. Https://portals.iucn.org/library/sites/ library/files/documents/WCC-5th-o02.pdf [accessed 15 March 2018].

Livingstone, E. \& Shepherd, C.R. (2016) Bear farms in Lao PDR expand illegally and fail to conserve wild bears. Oryx, 50, 176-184.

Loeffler, I.K., Robinson, J. \& Cochrane, G. (2009) Compromised health and welfare of bears farmed for bile in China. Animal Welfare, 18, 225-235.

MAAs, B. (2000) The veterinary, behavioural and welfare implications of bear farming in Asia. World Society for the Protection of Animals, London, UK.

Newing, H. (2011) Conducting Research in Conservation: Social Science Methods and Practice. Routledge, Abingdon, Oxon, UK.

NGUYen, X.D. (2007) Bear parts trade in Vietnam and measures for its control. In 4 th International Symposium on the Trade in Bear Parts (ed. D. Williamson), pp. 61-66. TRAFFIC East Asia, Nagano, Japan.

Nijman, V., Oo, H. \& Shwe, N.M. (2017) Assessing the illegal bear trade in Myanmar through conversations with poachers: topology, perceptions, and trade links to China. Human Dimensions of Wildlife, 22, 172-182.

Scotson, L., Fredriksson, G., Augeri, D., Cheah, C., Ngoprasert, D. \& Wai-Ming, W. (2017) Helarctos malayanus. The IUCN Red List of Threatened Species. Https://doi.org/10.2305/ IUCN.UK.2017-3.RLTS.T9760A45033547.en [accessed 23 May 2018].

Tensen, L. (2016) Under what circumstances can wildlife farming benefit species conservation? Global Ecology and Conservation, 6, 286-298.

Venkataraman, B. (2007) A matter of attitude: the consumption of wild animal products in $\mathrm{Ha}$ Noi, Viet Nam. TRAFFIC Southeast Asia, Greater Mekong Programme, Ha Noi, Viet Nam.

Vu, Q.T. (2010) An Analysis of Attitudes and Bear Bile use in Vietnam. Education for Nature-Vietnam (ENV), Hanoi, Viet Nam.

Wilcove, D.S., Giam, X., Edwards, D.P., Fisher, B., \& Koh, L.P. (2013) Navjot's nightmare revisited: logging, agriculture, and biodiversity in Southeast Asia. Trends in Ecology \& Evolution, 28, 531-540.

Willcox, D., Minh, N.D.T. \& Gomez, L. (2016) An assessment of trade in bear bile and gall bladder in Viet Nam. TRAFFIC, Petaling Jaya, Selangor, Malaysia.

\section{Biographical sketches}

BRIAN CRUDGE's research interests include species conservation, wildlife trade, bear ecology, animal welfare, traditional medicine, and public attitudes and perceptions towards wildlife. TRANG NGUYEN's research interests include wildlife trade, the use of animals in traditional medicine, and consumer perceptions and behaviours. Cao Tien Trung's research interests lie in assessing the status and distribution of wildlife populations, and conservation of large mammals in Viet Nam. 